\title{
Evidence to End FGM/C Research Programme: Presentation at the sixtieth session of the UN Commission on the Status of Women
}

Jacinta Muteshi-Strachan

Population Council

Follow this and additional works at: https://knowledgecommons.popcouncil.org/departments_sbsr-rh

Part of the Demography, Population, and Ecology Commons, Family, Life Course, and Society Commons, International Public Health Commons, Maternal and Child Health Commons, Sociology of Culture Commons, and the Women's Health Commons How does access to this work benefit you? Let us know!

\section{Recommended Citation}

Muteshi-Strachan, Jacinta. 2016. "Evidence to End FGM/C Research Programme: Presentation at the sixtieth session of the UN Commission on the Status of Women." New York: Population Council. 


\section{Evidence to (\%)
End FGM/C}

The sixtieth session of the Commission on the Status of Women United Nations Headquarters in New York. 14 to 24 March 2016.

Jacinta Muteshi

Population Council

March 2016 


\section{Introduction \\ The Evidence to End FGM/C Research Programme}




\section{Why a research programme on FGM/C?}

$\checkmark$ Intensive Africa-led advocacy in the past decade has led to widespread agreement on the need for intensifying efforts to end FGM/C within one generation

$\checkmark$ Historically low levels of funding for FGM/C research has led to a global evidence base suffering from many critical gaps

Global and national efforts to end FGM/C rapidly can be more effective and efficient when informed by high quality evidence generated through rigorous, ethical and appropriate research 


\section{Our goal for 2020}

DFID's Programme 'Towards Ending FGM/C in Africa and Beyond'

3 components

- Population Council

- UNFPA-UNICEF Joint Programme on FGM/C: accelerating change

- The Girl Generation

Duration: 2016 - February 2020

\section{Contribute to Impact}

End to the practice in one generation and a reduction in the practice by $30 \%$ in at least ten countries within five years

\section{Research Goal}

Generate evidence to influence strategic investments, policies, and programs to end $\mathrm{FGM} / \mathrm{C}$ 


\section{Key principles guiding our work:}

1. Doing no harm

2. Supporting an African led movement for FGM/C abandonment

3. Understanding FGM/C within the wider context of violence and discrimination against women and girls 


\section{Geographic focus: 7 countries}

\section{Criteria}

Scale of the practice: Six countries with combined population of over 90 million girls and women who have been cut, $70 \%$ of total

Represent all 5 stages of transition in abandonment

Socio-cultural variations

UNJP and TGG programming and intervention priority countries

VfM through cost-effective programme implementation:

Experienced research teams available in all six countries; Consortium managed within the region; Partners able to work in Anglophone, Francophone and Arabic contexts

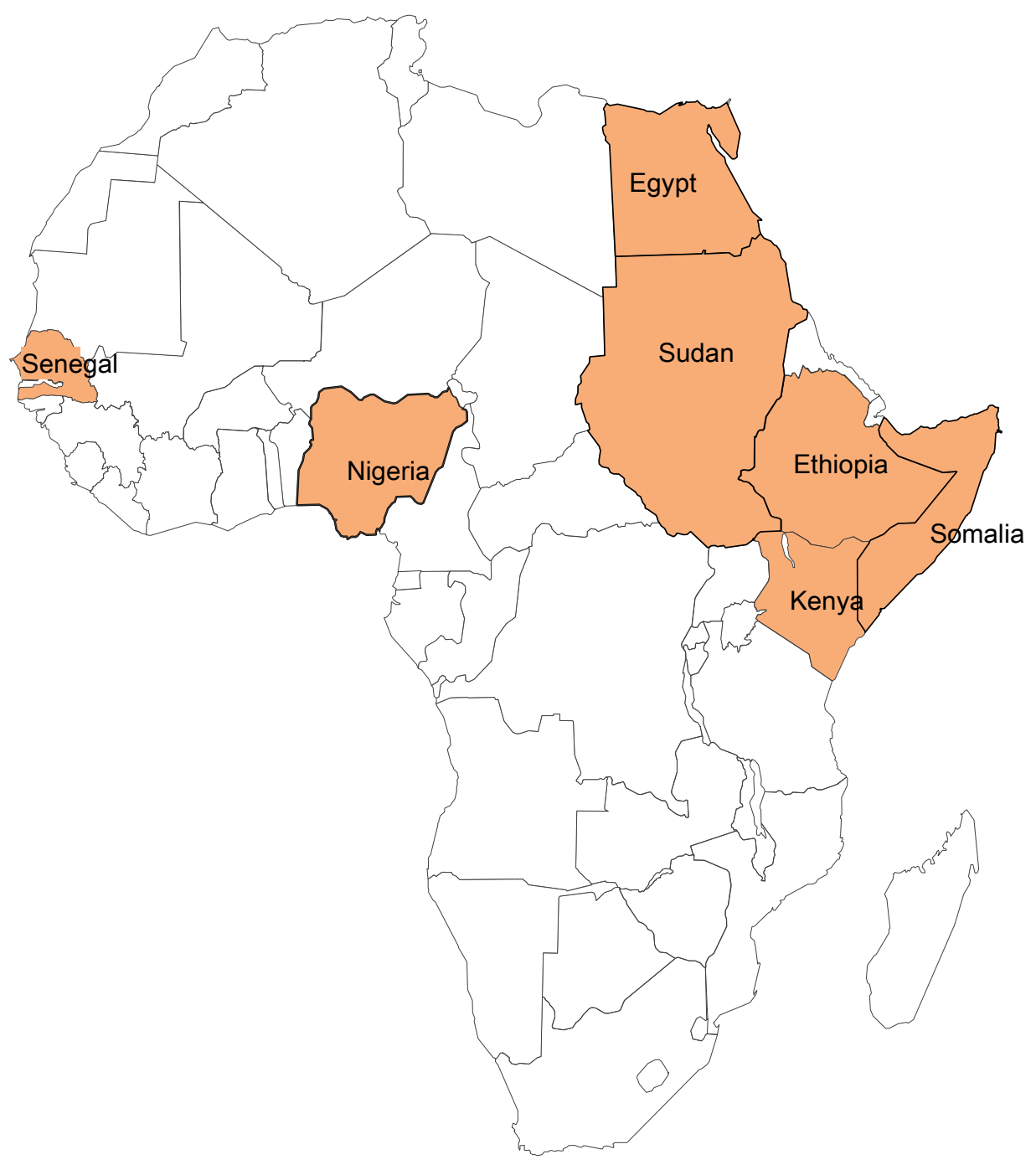




\section{Consortium Partners}

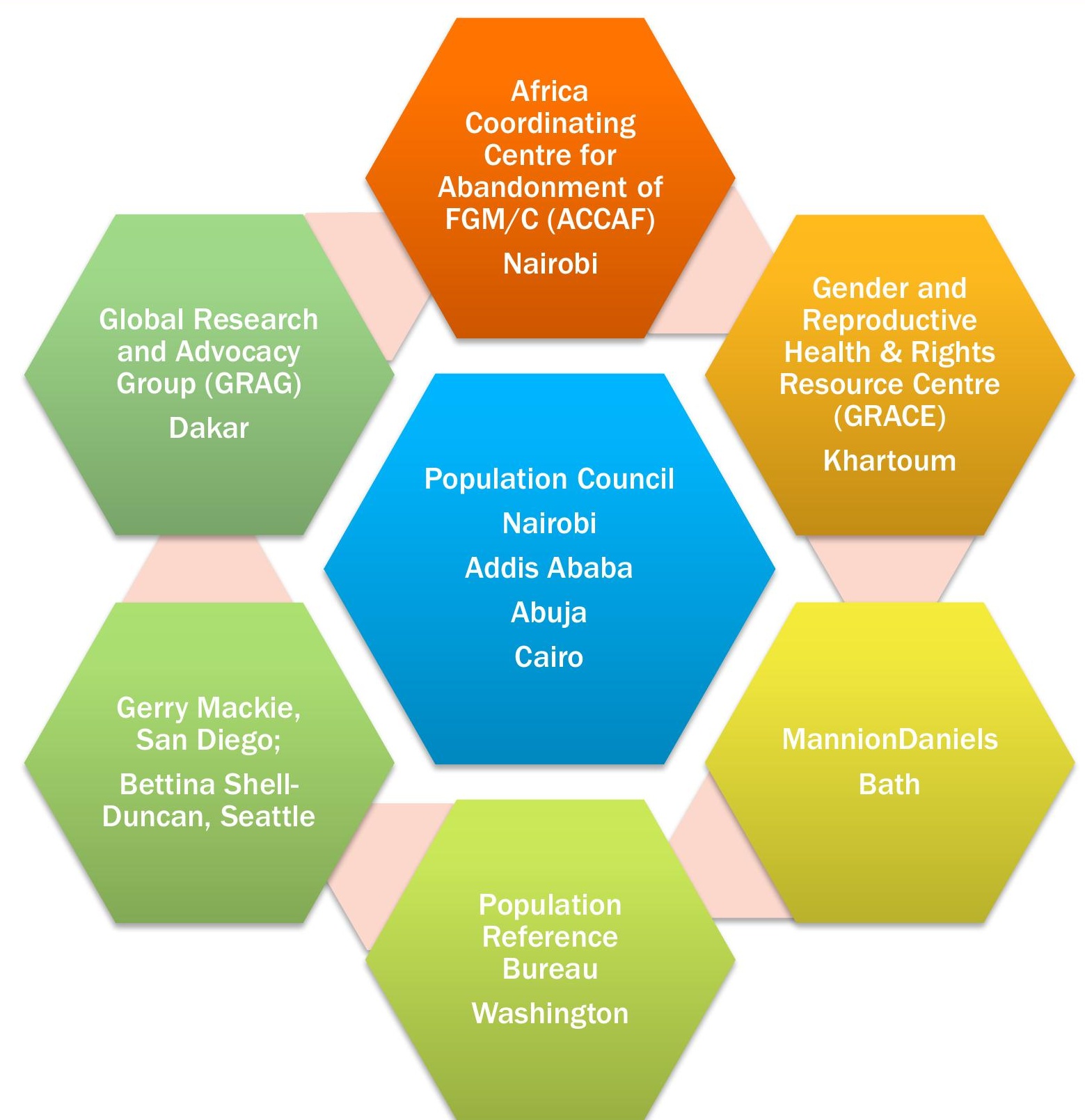




\section{More evidence needed on the best strategies for ending FGM/C including :}

1.Knowledge of the drivers and consequences of $\mathrm{FGM} / \mathrm{C}$ in specific contexts, to build a detailed understanding that also enables generalizations

2.Impact of $\mathrm{FGM} / \mathrm{C}$ interventions, which requires strengthened monitoring and evaluation frameworks and systems

3.Need for more work on research methods to strengthen available data

4.Need for more attention to theory-based intervention and evaluation designs

5.Improved coordination efforts to ensure greater research utilization 


\section{Research Agenda}

Four research themes

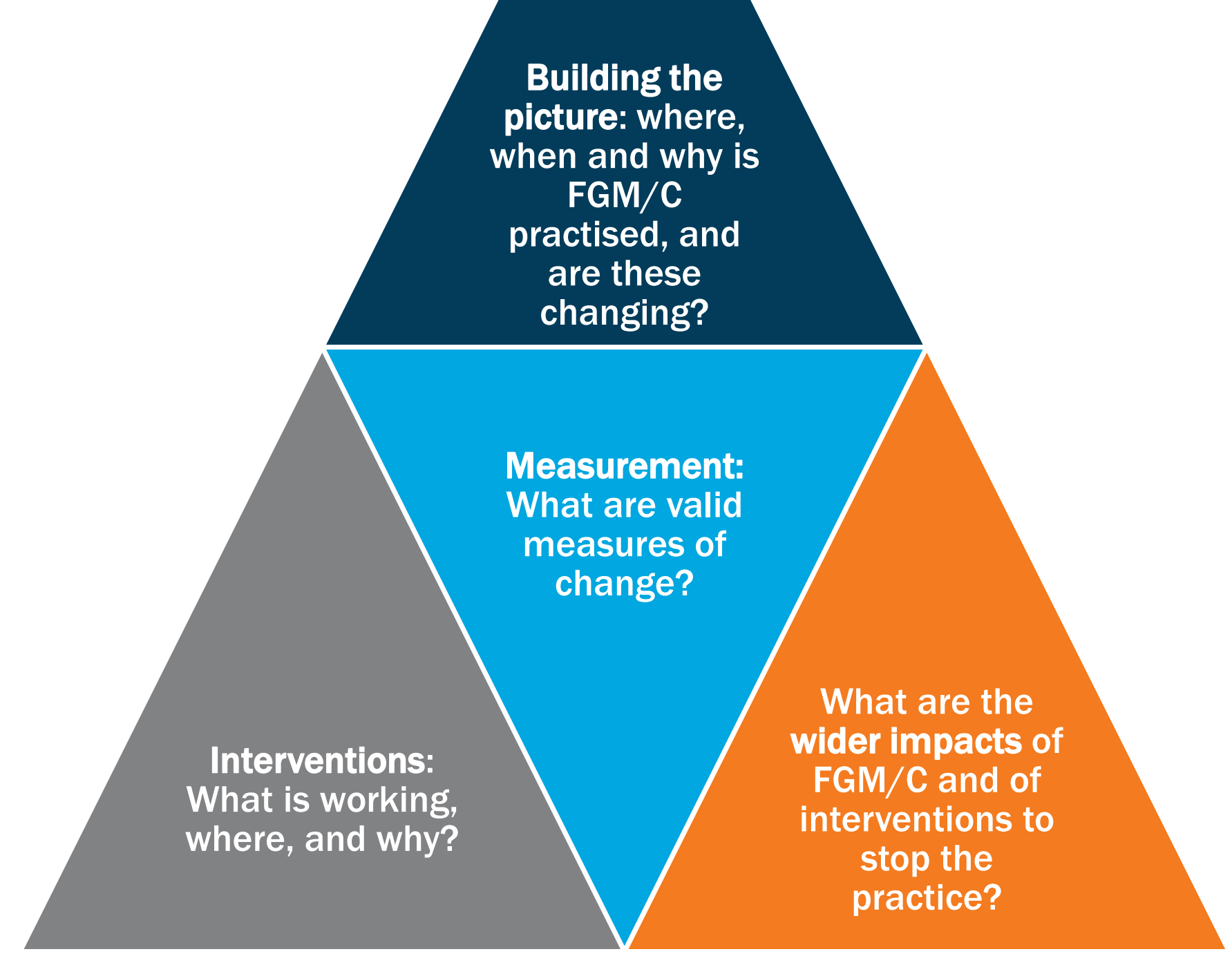




\section{Theme 1: Building the picture \\ Where, when and why is FGM/C practised, and are these changing?}

1. Identifying and explaining generational shifts in FGM/C attitudes and practice;

2. Differentiating individual and community

abandonment factors with multilevel and spatial analyses;

3. How gender affects the continuation or abandonment of FGM/C;

4. Understanding the factors influencing abandonment of FGM/C;

5. Understanding shifts in the nature of the practice to sustain FGM/C. 


\section{Theme 2: Interventions}

\section{What's working, where and why?}

1. Changing social norms through social networks, community values deliberations, and public declarations

2. De-linking $\mathrm{FGM} / \mathrm{C}$ as a religious obligation and engaging religious leaders as change agents

3. Strengthening health systems to engage health professionals as change agents

4. Creating new perspectives and expectations of gender norms for uncut girls and women through multi-channel 'social marketing' campaigns

5. Legislation and policy reform as programmed interventions and/or enabling conditions 
Theme 3: What are the wider impacts of FGM/C on the lives of girls, women and their families and the implications of sustaining or abandoning the practice as well as other harmful practices ?

1. Adverse health impacts

$\checkmark$ obstetric; gynaecological; sexual; mental health

2. Potential associations between $\mathrm{FGM} / \mathrm{C}$ and:

$\checkmark$ HIV; Infertility; Fistula

3. Potential associations between FGM/C and women's sexuality and psychological well-being

4. Potential social tensions associated with rapid social norms changes

$\checkmark$ Early abandoners

$\checkmark$ Late / non abandoners

5. Whether and how FGM/C-focused interventions have wider impacts on gender relations, early marriage and violence 


\section{Theme 4: Measurement What are valid measures of change?}

1. Addressing the challenges of ethically and accurately measuring prevalence and FGM/C status;

2. Improving designs to evaluate complex interventions commonly used for FGM/C abandonment;

3. Enhancing the application of "theory of change" to evaluation of FGM/C abandonment interventions;

4. Improving the definition and measurement of social norms and norms' changes;

5. Increasing the rigour, relevance and utility of published descriptions of FGM/C interventions and their evaluation 


\section{Implementing the research programme}




\section{Our Theory of Change}

\section{Stakeholder engagement}

\section{Generation of high quality evidence}

\section{Evidence communication}

Capacity building for researchers and stakeholders

Monitoring and evaluation 


\section{Some of the key achievements}

Stakeholder engagement

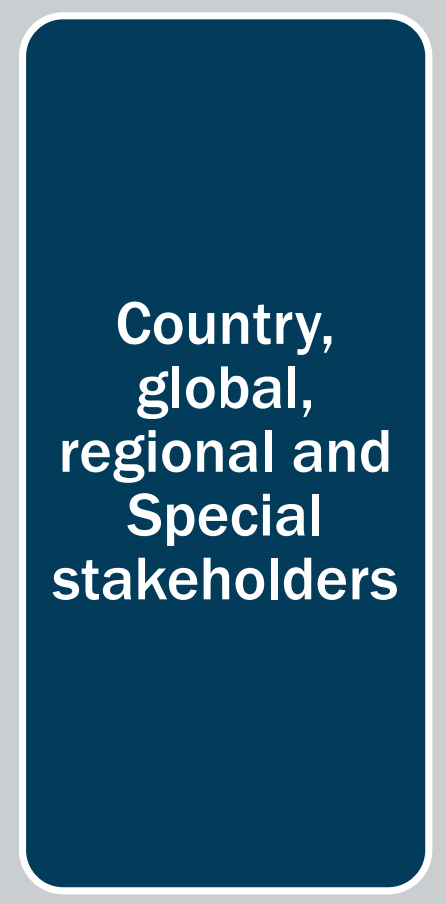

Generating evidence

Synthesis products

$\Xi T h e$ online compendium of FGM/C Interventions http://67.205.63.199/fgmc/

WState of the art synthesis of FGM/C: What do we know in 2015

Synthesis of the

Evidence on the Health Impacts of FGM/C

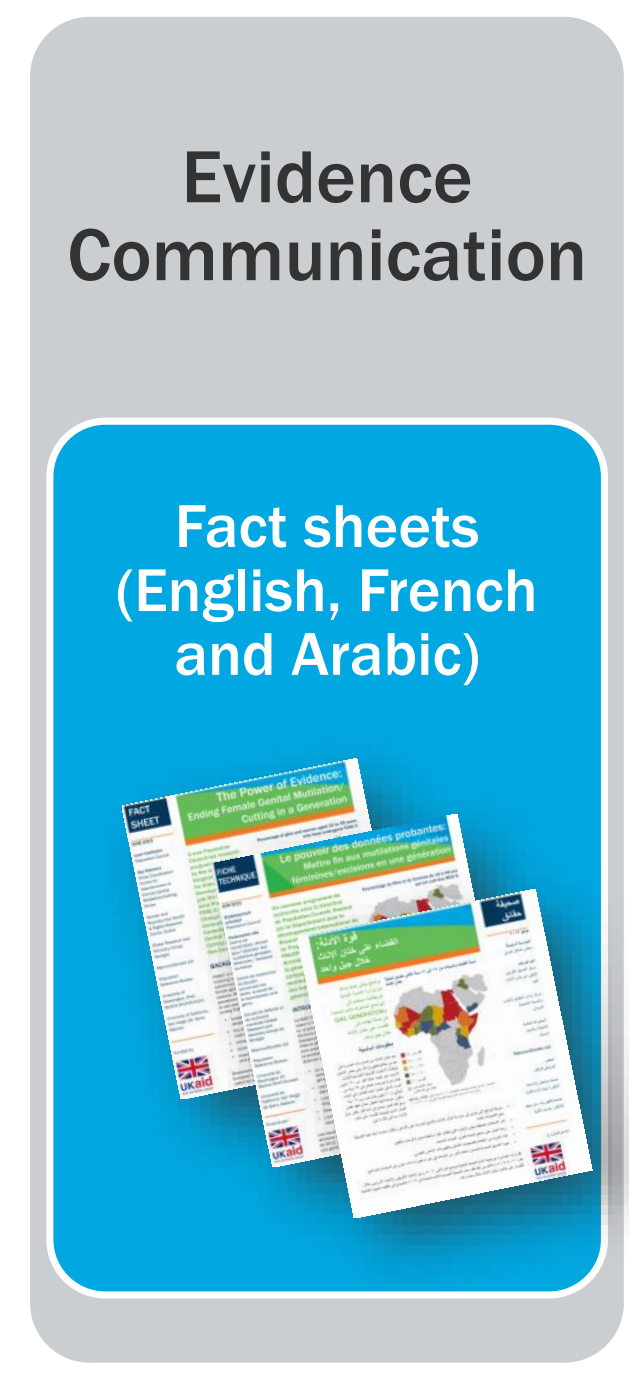

Capacity building

\section{Trainings}

Research skills of UNFPA-UNICEF stakeholders for Somalia

Social Norms Workshop for all consortium partners 


\section{Evidence to End FGM/C}

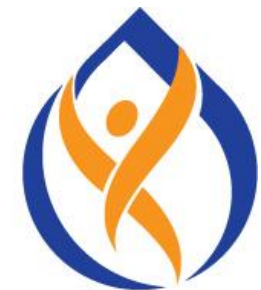

Research to Help Girls and Women Thrive

The Evidence to End FGM/C programme consortium generates evidence to inform and influence investments, policies, and programs for ending female genital mutilation/cutting in different contexts.

Evidence to End FGM/C is led by the Population Council in partnership with the Africa Coordination Centre for Abandonment of Female Genital Mutilation/Cutting (Kenya); Gender and Reproductive Health \& Rights Centre (Sudan); MannionDaniels, Ltd.; Population Reference Bureau; University of California, San Diego; and University of Washington. Evidence to End FGM/C is funded by UK aid by the UK Government.

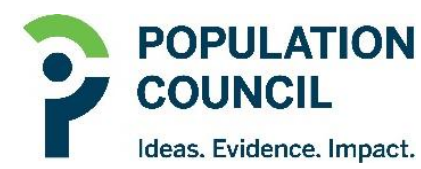

Ideas. Evidence. Impact.
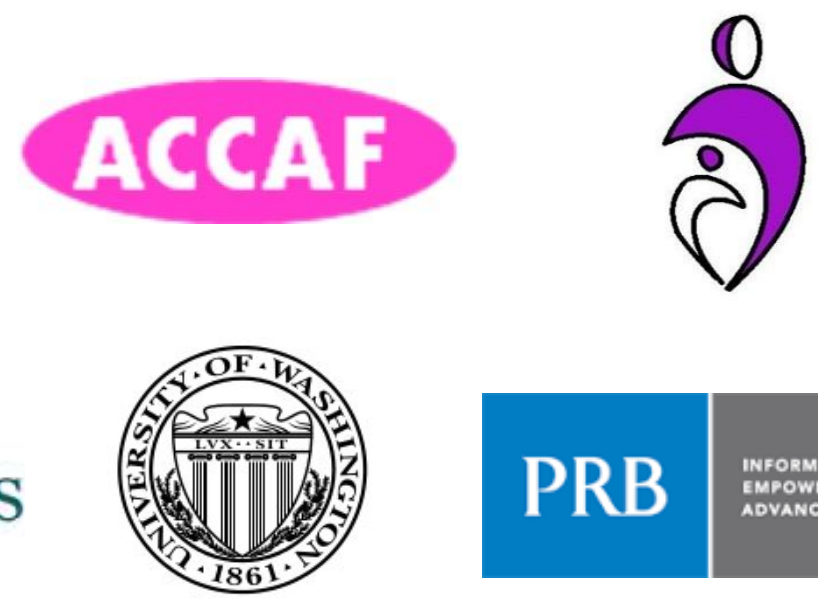

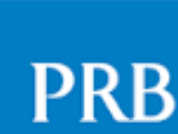

INFORM

EMPOWER

ADVANCE
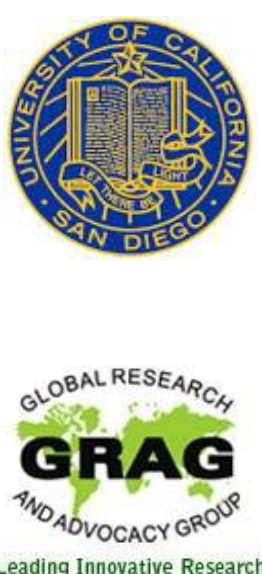

\section{MannionDaniels}

